\title{
ZUSGS
}

.

\section{Eruptions in the Cascade Range During the Past 4,000 Years}

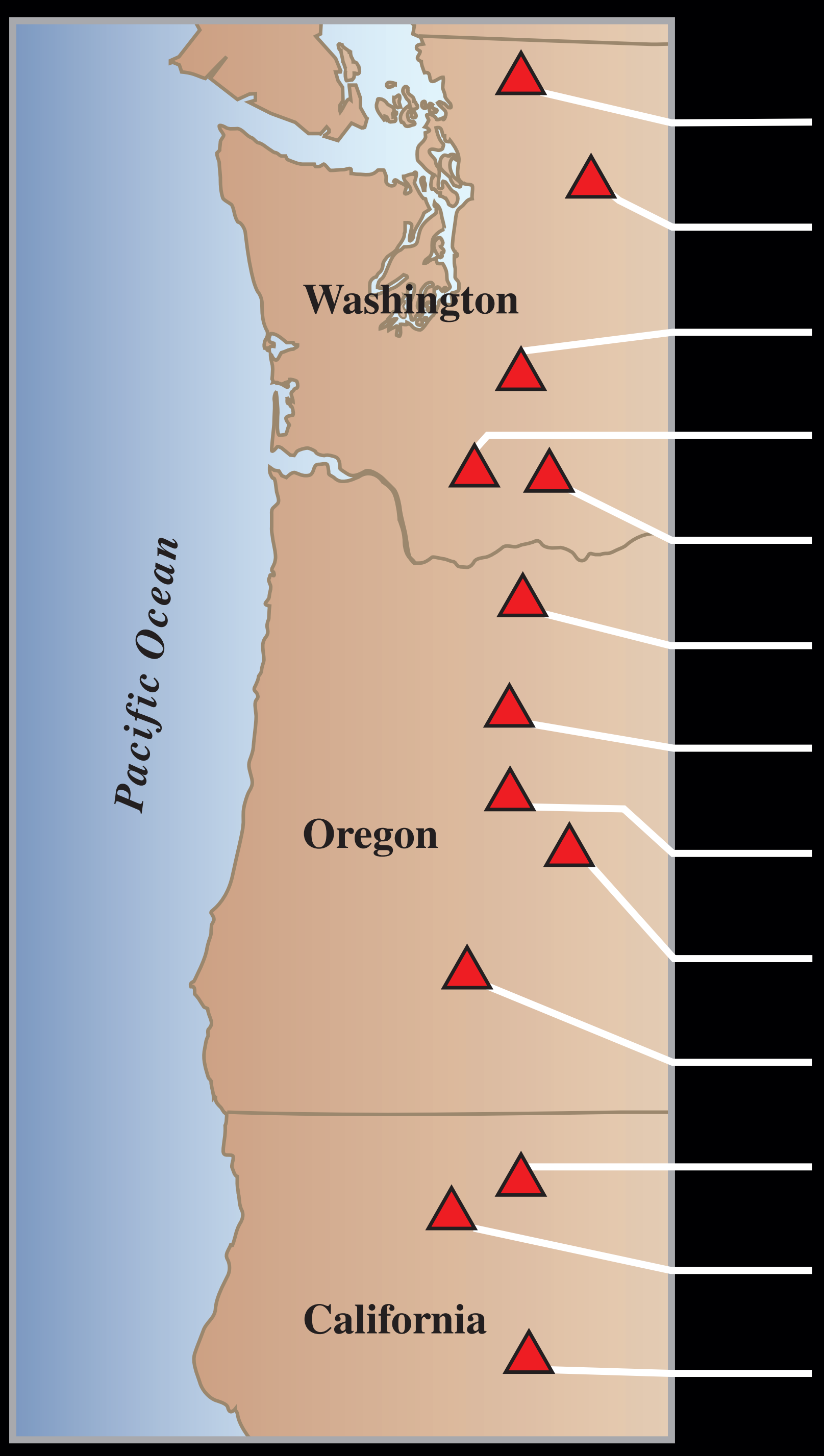

Volcanoes have been erupting in the Cascade Range for over 500,000 years. During the past 4,000 years eruptions have occurred at an average rate of about 2 per century.

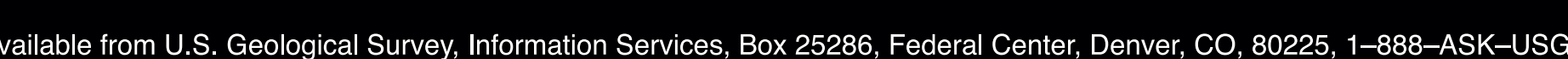
Doitial files avaliable at hthp://pubs. usgs. gov/gip/63
Mount Baker

Glacier Peak

Mount Rainier

Mount St. Helens

Mount Adams

Mount Hood

Mount Jefferson

Three Sisters

Newberry Volcano

Crater Lake

Medicine Lake Volcano

Mount Shasta

Lassen Peak

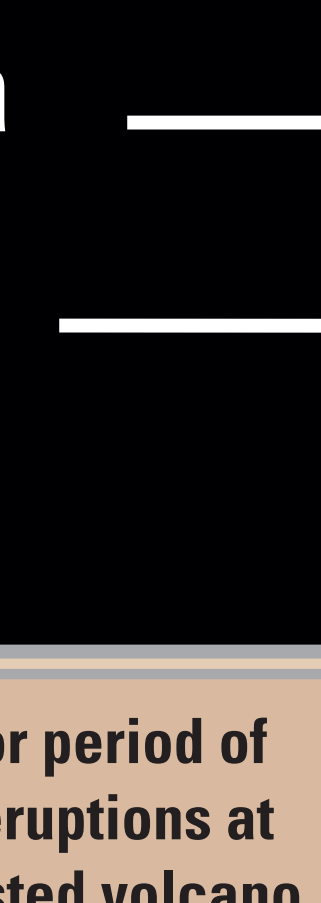

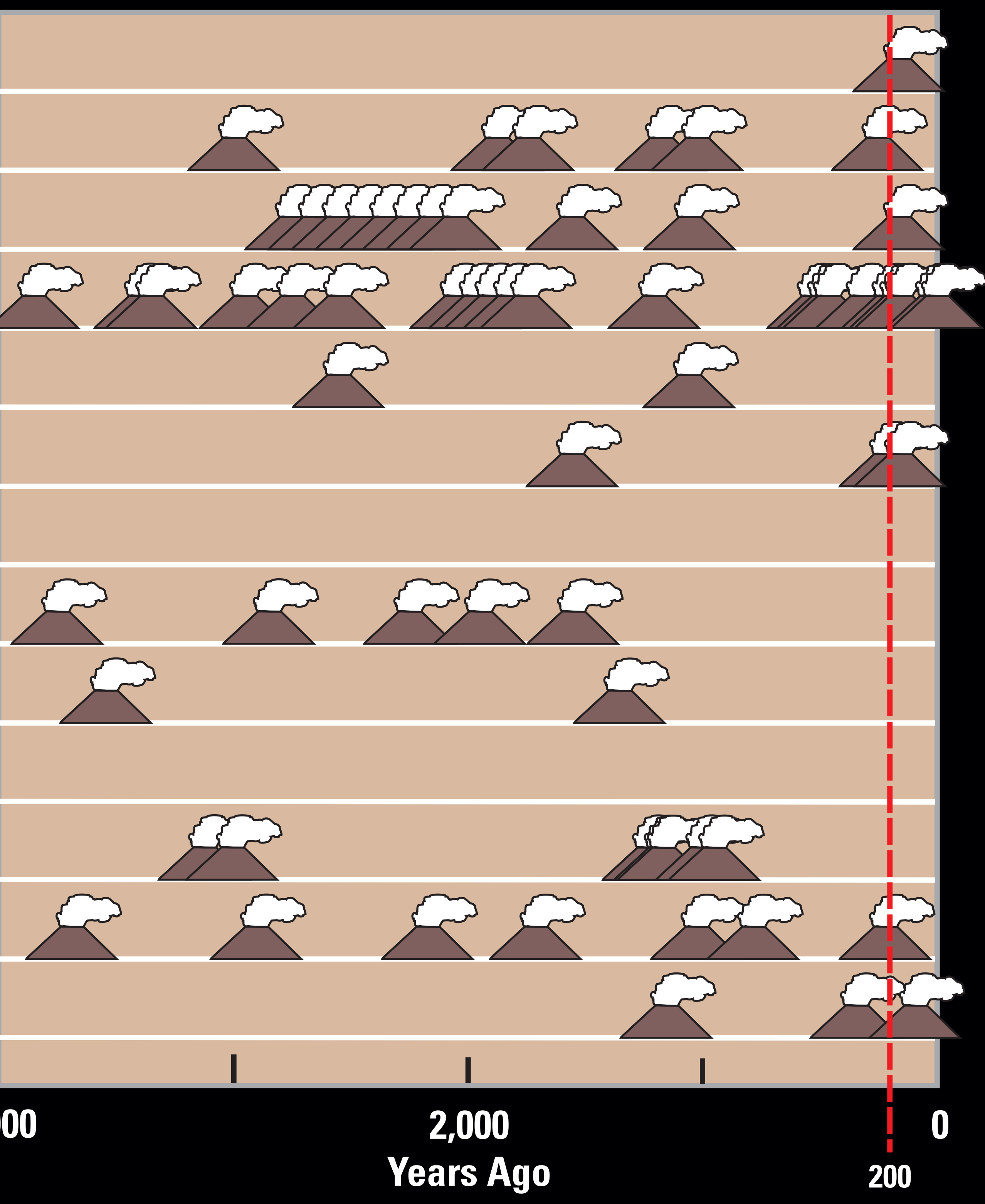

By Bobbie Myers and Carolyn Driedger

$$
2008
$$

